Nachruf

Gynäkologische Endokrinologie 2020 • 18:260 https://doi.org/10.1007/s10304-020-00347-6

(c) The author(s) 2020

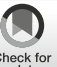

Check for
updates

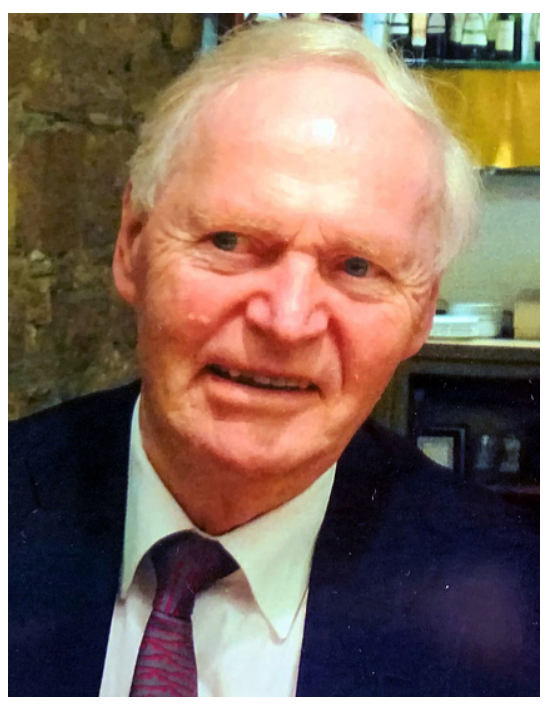

Abb. 1 ム Professor Dr. med. em. Meinert Breckwoldt. (Mit freundl. Genehmigung, $\odot$ Dr. Tina Breckwoldt, Wien, alle Rechte vorbehalten)

Professor Dr. med. em. Meinert Breckwoldt (• Abb. 1) wurde am 14.11.1934 als Sohn einer Kapitänsfamilie in Wittdün auf Amrum geboren, wo er seine Kindheit und Jugend friesisch-sprechend verbrachte. Die tiefe Verbundenheit zu seiner Insel, zu den Dünen und zum Meer wie auch zu seinen Eltern hat er zeit seines Lebens nie verloren. Nach Studium und Fachausbildung in Kiel, Marburg, München, Hamburg und Philadelphia (USA) wechselte er mit seiner Familie nach Freiburg i. Br. über. Hier war er von 1973 bis 2000 in leitenden Funktionen, zunächst als Abteilungsleiter für gynäkologische Endokrinologie und Fortpflanzungsmedizin, später als ärztlicher Direktor der Universitätsfrauenklinik, Freiburg i. Br., tätig. Zusammen mit Bruno Lunenfeld (Tel Aviv) und Ger-

Franz Geisthövel ${ }^{1} \cdot$ Herbert Kuhl $^{2}$

${ }^{1}$ Vörstetten/Freiburg i. Br., Deutschland

${ }^{2}$ Aschaffenburg, Deutschland

\title{
Nachruf zum Tode von Professor Dr. med. em. Meinert Breckwoldt
}

\author{
14.11.1934-21.07.2020
}

hard Bettendorf (Hamburg) gehörte er zu den Pionieren der Gonadotropintherapie, mit der - in zuvor nicht gekannter Wirksamkeit - kinderlosen Frauen zu einem Kind verholfen werden konnte. Für die Neugestaltung der israelischdeutschen Beziehungen innerhalb der Wissenschaftsgemeinde war gerade das enge Freundschaftsverhältnis zwischen diesen dreien und auch dem israelischen Endokrinologen Vaclav Insler wegweisend. Als Urgestein der gynäkologischen Hormonheilkunde und Fortpflanzungsmedizin verfügte Meinert Breckwoldt über ein breit vernetztes theoretisches Wissen, das er mit großer klinischer Erfahrung verknüpfte. Sein von ärztlicher Empathie getragener Dienst an seinen Patientinnen und sein hohes Verantwortungsgefühl für die gesamte Frauenklinik in Verbindung mit Lehre, Wissenschaft und Forschung bildeten bei ihm eine konzeptionelle Einheit. Zu den besonderen Schwerpunkten zählten die Endokrinologie der Pubertät, die Genese, Diagnostik und Therapie der ungewollten Kinderlosigkeit, die Endokrinologie der Schwangerschaft und Stillzeit sowie die sexuelle Differenzierung, Intersexualität und Androgenisierung der Frau. An der Entwicklung der hormonalen Kontrazeption und der Hormontherapie in der Peri- und Postmenopause war er von Anfang an beteiligt. Über viele Jahre war er als Gutachter für das Bundesgesundheitsamt tätig. Unter seiner fürsorglich-väterlichen Führung promovierten zahlreiche Doktorandinnen und Doktoranden, und 14 seiner Schüler gelang die Habilitation. Als Autor und Koautor von über 300 wissenschaftlichen
Publikationen, zahlreichen Buchbeiträgen und Monographien, als Herausgeber der Fachzeitschrift Geburtshilfe und Frauenheilkunde sowie als Mitglied des „Züricher Gesprächskreises“ erwarb er sich national und international große wissenschaftliche Anerkennung. Für seine Verdienste wurde er im Jahre 1995 mit der Laqueur-Medaille ausgezeichnet und 2005 zum Ehrenmitglied der Deutschen Gesellschaft für Endokrinologie ernannt. Weiterhin wurde er aufgrund seiner Verdienste mit der Ehrenmitgliedschaft im Freundeskreis FreiburgTel Aviv-Yafo ausgezeichnet. So war er als Arzt, Wissenschaftler und Lehrer ein Vorbild für viele Studenten wie auch für junge und ältere Kollegen, all dies geprägt von seinem feinsinnigen nordfriesischen Humor und seiner Menschlichkeit. Professor Meinert Breckwoldt verstarb am 21.07.2020 in Freiburg und wurde inzwischen auf seiner geliebten Insel Amrum beigesetzt.

Prof. Dr. med. Franz Geisthövel, Vörstetten/Freiburg i. Br.

Prof. Dr. med. Herbert Kuhl, Aschaffenburg

Vörstetten/Aschaffenburg, 04.08.2020

\section{Korrespondenzadresse}

Prof. Dr. med. Franz Geisthövel

Stahlenhofgasse 10, 79279 Vörstetten/

Freiburg i. Br., Deutschland

fgeisthoevel@gmail.com 